\title{
Can Fixed Regular Deposits Overcome Savings Constraints?*
}

\begin{abstract}
Anett John ${ }^{\dagger}$
Abstract

Empirical evidence from developing countries suggests that there is a high demand for informal savings mechanisms even though these often feature negative returns - such as deposit collectors, ROSCAs, microloans, and informal borrowing. Why do people not just save at home, instead of relying on such costly devices? In a savings model with hyperbolic discounting and uncertainty, I show why a commitment to fixed regular savings deposits can help individuals to achieve the welfare-maximising level of savings, when they would not be able to do so on their own. Such regular-instalment commitment products further increase welfare by smoothing savings contributions. The setting is enriched by endogenising take-up, and giving individuals the ability to choose their own commitment stakes. The results point to the possibility that the observed demand for costly informal savings devices may simply represent a demand for commitment savings products with fixed periodic contributions, as they are commonly offered by banks in rich countries.
\end{abstract}

Keywords: commitment savings, hyperbolic discounting, regular instalments

JEL classification: C93, D03, D14, O12

${ }^{*}$ This article is a shortened version of chapter 2 of my dissertation. A longer version was previously circulated under the name Anett Hofmann, and the title "Just A Few Cents Each Day: Can Fixed Regular Deposits Overcome Savings Constraints? - Evidence from a Commitment Savings Product in Bangladesh.” I am grateful to the editors, Fabrice Le Lec and Nicolas Jacquemet, as well as an anonymous referee for detailed feedback that improved the paper. I would like to thank my advisors, Oriana Bandiera, Maitreesh Ghatak, and Gharad Bryan, for their invaluable support and advice. Thanks to Stefano DellaVigna, Jonathan de Quidt, Dean Karlan, Matthew Levy, George Loewenstein, Johannes Spinnewijn and Erina Ytsma for helpful comments and discussions. All errors and omissions are my own.

†CREST, email: anett.john@ensae.fr. 


\section{Introduction}

There are many reasons why even individuals with very low incomes have the need to convert small everyday sums of money into larger lump sums. Among them are life-cycle needs (such as marriage, childbirth, education or home building), insurance against emergencies (like sickness, loss of employment, natural disasters) and business opportunities (e.g. buying land or a new machine). To obtain these lump sums, individuals use a variety of financial services - many of which are very costly. One example is the popularity of costly or inflexible savings mechanisms. The United States has a long tradition of Christmas Clubs - savings programs which ask clients to deposit small amounts of money each week until December, at low or zero interest rates, and fees for early withdrawal. First recorded in 1909, they continued to attract 10 million clients in 1995 (Crosgrave (1927), Laibson et al. (1998)). In a developing context, the wandering deposit collectors found in South Asia and Africa charge negative interest rates in return for collecting people's savings. ${ }^{1}$ Similarly, rotating savings and credit organizations (ROSCAs) are prevalent all across the developing world (e.g. Besley, Coate and Loury (1993), Gugerty (2007)). While ROSCAs are costless, they are inflexible to an individual member's needs.

In a similar vein, observational evidence from developing countries indicates a popularity of borrowing for consumption purposes, as well as for periodic business expenses (e.g., to maintain stock). ${ }^{2}$ In both cases, obtaining a loan is not essential to generating the income that will repay it: Many clients go through a loan cycle every month for years, paying back in small instalments every week. A savings cycle with frequent contributions differs from this in one initial loan disbursement, which pales in size compared to annualized interest rates between 100 and 500 percent. ${ }^{3}$ Given such interest rates, the decision to borrow rather than to save seems puzzling.

Why do people not just save at home, instead of relying on such costly devices? An answer suggested in the existing literature are (quasi-)hyperbolic preferences. ${ }^{4}$ Hyperbolic discounters are impatient over current tradeoffs (now vs. tomorrow) and patient over future trade-offs (one year vs. one year plus one day). As a result, they procrastinate saving. This leads either to failure to reach their savings target, or to a failure to smooth consumption by saving too much in the last minute. If hyperbolic individuals realize their time inconsistency, they will be willing to pay for commitment products which force them to save. Recent empirical literature has confirmed a link between hyperbolic discounting and a preference for commitment (see Ashraf, Karlan and Yin (2006), Bauer, Chytilova and Morduch (2012), and Gugerty (2007)).

This paper shows theoretically how hyperbolic discounters can benefit from a commitment to fixed regular savings deposits. In doing so, it suggests that the empirical popularity of inflexible ROSCAs, costly deposit collectors, Christmas Clubs, and (partly) of microcredit and informal borrowing may simply represent a demand for commitment savings products with fixed periodic contributions (hereafter: "regular saver product"). Using a model of hyperbolic discounting, it is shown that individuals cannot reach their welfare-maximising level of savings at home, and that a regular saver product can increase their achievable savings level, as well as smooth savings contributions over time.

The existing literature on formal commitment savings has focused largely on savings products featuring withdrawal restrictions, but without an obligation to deposit in the first place. ${ }^{5}$ For a hyperbolic discounter, simply giving him the opportunity to restrict his withdrawals will not do - he will be prevented from touching past savings, but will have no incentive to contribute further. A demand for commitment to frequent instalments has been previously hypothesised in Rutherford (2000) and Bauer, Chytilova and Morduch (2012), but not modelled the-

\footnotetext{
${ }^{1}$ See e.g. Besley (1995) and Rutherford (2000).

${ }^{2}$ See e.g., Collins et al. (2009), the Indian vegetable vendors studied in Ananth, Karlan and Mullainathan (2007), or Rutherford (2000).

${ }^{3}$ See e.g., Rutherford (2000) or Ananth, Karlan and Mullainathan (2007).

${ }^{4}$ Most prominently, Laibson (1997) and O’Donoghue and Rabin (1999).

${ }^{5}$ See e.g. Ashraf, Karlan and Yin (2006), Brune et al. (2016), Karlan et al. (2016), and Giné, Karlan and Zinman (2010).
} 
oretically. A related theoretical contribution is Fischer and Ghatak (2010), who show in a deterministic setting that incentive-compatible loan sizes increase with repayment frequency. Related empirical contributions include Dupas and Robinson (2013) and Kast, Meier and Pomeranz (2014), who study social commitments to regular deposits, as well as Benartzi and Thaler (2004), who study 401(k) pension contributions with default options. In a very recent contribution, Afzal et al. (2015) test the savings-versus-loan choice in a lab-in-the-field setting.

In a savings framework that includes uncertainty as well as a motive for consumption smoothing, I show the effects of a regular-instalment product on savings levels, consumption paths, and welfare. The adoption decision is endogenised. Given fully sophisticated agents, offering a regular saver product increases the range of preferences where a savings goal (a nondivisible good) can be reached. Savings contributions are smoothed towards a balanced savings path. The setting is enriched by allowing individuals to choose their own "commitment stakes", specifically, the penalty they pay upon defaulting on the savings plan. An extension shows the effects on the demand for loans.

Uncertainty plays a key role in the model: In a deterministic setting, commitment is costless. There are no disadvantages to imposing infinitely large penalties on undesirable behaviour. Thus, as long as such commitments are technically feasible, the agent can always achieve the first-best savings behaviour by imposing large penalties on non-compliance. More realistically, individuals face uncertain environments, which create a demand for flexibility. For instance, the arrival of an income shock may mean that saving is no longer optimal. Amador, Werning and Angeletos (2006) study this trade-off between commitment and flexibility in a generalised setting, where the planner directly controls the choice set. In the current setting, where commitment is implemented using penalties, it creates an interesting dynamic interaction: Conditional on being unable to save for a nondivisible expense in autarky, the most time-inconsistent individuals are the least likely to adopt commitment, since they require the largest stakes.

The model builds on Basu (2014), who focuses on withdrawal-restriction products and supply-side variations. It is consistent with Amador, Werning and Angeletos (2006)'s general result that trade-offs between commitment and flexibility are optimally solved with minimum-savings requirements. Finally, it generalizes the model in John (2016) for multiple periods, concave utility, and regular instalments.

\section{Theory: Hyperbolic Discounting and Regular Instalments}

The following section attempts to provide a theoretical foundation which justifies the need to provide regular saver commitment products when agents have time-inconsistent preferences and face uncertainty. The benchmark model without banking services is based on Basu (2014), but departs from it in the design of the commitment savings product as well as in the presence of shocks.

\subsection{The Model}

Consider an agent who decides whether to save up for a nondivisible good (such as school tuition fees, a new roof, or a medical treatment) which costs $2<p<3$ and yields a monetary benefit $b>3$. The agent lives for three periods and receives a per period income of $y_{t}=1$, which he can either consume immediately or save. ${ }^{6}$ He cannot borrow. His instantaneous utility function is concave and satisfies the Inada conditions, specifically,

\footnotetext{
${ }^{6}$ Three periods are sufficient to illustrate the main mechanism of the model, which deals largely with the savings coordination between periods 1 and 2. It is straightforward to extend the model to $N \geq 3$ periods, in which case the savings burden is allocated between periods 1 and $N-1$ (in period $N$, the choice is trivial). All main results hold with $N$ periods.
} 
$u^{\prime}(c)>0, u^{\prime \prime}(c)<0$, and $u^{\prime}(0)=\infty$. His lifetime utility as evaluated in each period is the discounted sum of the instantaneous utilities: ${ }^{7}$

$$
U_{t}=u\left(c_{t}\right)+\beta \sum_{k=t+1}^{3} u\left(c_{k}\right)
$$

When $\beta<1$, the discount rate between the current period $t$ and $t+1$ is lower than the discount rate between subsequent periods - i.e. the agent exhibits a present bias. The model will assume that he is sophisticated-i.e., he realizes that his future selves will display the same present bias that he has, resulting in an inconsistency between the preferences of his current self and those of his future selves. The model further assumes that there is no other form of discounting ( $\delta=1$ ), and that the gross return on savings is $\rho=1$ in both the autarky and the banking scenario. This isolates the effect of a commitment to regular instalments, since it is not profitable for individuals to use banking services simply to gain higher returns.

The agent faces uncertainty through income shocks: Each period, his income is lost with a probability of $\lambda$. A single shock is sufficient to reduce lifetime income to 2 , thus rendering the nondivisible good unattainable. The presence of shocks in the model thus captures a demand for flexibility. Interpretations of the shock range from genuine income shocks (unemployment, bad business) to unexpected vital expenses (hospital bills). More generally, $\lambda$ captures the probability that saving for the nondivisible good ceases to be optimal for any timeconsistent reason. Once hit by a shock, any existing savings are optimally spread over the remaining periods for consumption.

While the literature disagrees on how to evaluate the welfare of hyperbolic discounters, the paper follows O'Donoghue and Rabin (1999): The welfare of a hyperbolic discounter is what he would like to maximise in a hypothetical period 0, i.e., just before the start of his life: $W=U_{0}=u\left(c_{1}\right)+u\left(c_{2}\right)+u\left(c_{3}\right)$. I assume throughout that $b, p$ are such that it is welfare-maximising to save for the nondivisible. ${ }^{8}$

\subsection{Autarky Equilibrium}

Denote by $s_{t}$ the cumulative savings sent from period $t$ to $t+1$. The following analysis assumes that no shock has hit up to period $t$. If a shock does hit (i.e., if $y_{t}=0$ ), the agent immediately gives up any plans to save for the nondivisible, and instead spreads available savings $s_{t-1}$ optimally over the remaining periods. The first-best benchmark can be inferred from the behaviour of a time-consistent agent: An agent with $\beta=1$ will always buy the nondivisible, absent shocks. For $\lambda=0$, the optimal savings schedule is easy to infer: Given the agent's desire to smooth consumption over time, it is optimal for him to split the necessary savings burden of $p-1$ evenly over periods 1 and 2, and then spend his period 3 income plus accumulated savings on the good. The implied savings profile is $s_{1}=\frac{p-1}{2} \equiv \bar{s}, s_{2}=p-1=2 \bar{s}$. For $\lambda>0$, there is a precautionary savings motive, ${ }^{9}$ even if the agent does not intend to save for the nondivisible. Denote such precautionary savings $s_{t}^{N o}$. It can be shown that the optimal savings path is slightly increasing, i.e., $s_{1}<\bar{s} .^{10}$

\footnotetext{
${ }^{7}$ The initial model setup is partially quoted from John (2016). While the present paper uses a three-period model and concave utility to study the effect of regular instalments, John (2016) uses a two-period model and linear utility to show the effect of partial sophistication on commitment choices more generally.

${ }^{8}$ More specifically, I assume that $b, p$ are such that desirability holds given fixed equal savings instalments, $\bar{s} \equiv \frac{p-1}{2}$.

${ }^{9}$ Since expected income is $1-\lambda$, and realised income absent shocks is 1 , this precautionary savings motive follows from $u^{\prime \prime}(c)<0$, and does not require assumptions on $u^{\prime \prime \prime}(c)$.

${ }^{10}$ The probability of remaining shock-free (and thus obtaining the nondivisible) increases over time, from $(1-\lambda)^{3}$ ex-ante to $(1-\lambda)$ once period 2 has been reached without a shock. This makes it optimal to slightly skew the savings burden $p-1$ towards period 2 . To see this formally, note that expected utility decreases in $s_{1}$ when evaluated at $s_{1}=\bar{s}: d U / d s_{1}=(1-\lambda)^{2}\left[-u^{\prime}\left(1-s_{1}\right)+u^{\prime}\left(2+s_{1}-p\right)\right]+(1-$ $\lambda) \lambda\left[-u^{\prime}\left(1-s_{1}\right)+u^{\prime}\left(s_{1}-s_{2}^{N o}\right)\right]<0$ for $s_{1}=\frac{p-1}{2}>0.5$. By the envelope condition, $d U / d s_{1}=\frac{\partial U}{\partial s_{1}}+\frac{\partial U}{\partial s_{2}} \cdot \frac{\partial s_{2}}{\partial s_{1}}=\frac{\partial U}{\partial s_{1}}$.
} 
If $\beta<1$, the three period selves engage in strategic interaction. Savings behaviour can be analysed using backward induction: The period 3 agent buys the good whenever his assets are sufficient, i.e., whenever $s_{2} \geq p-1$, and absent shocks. Excess savings, as well as savings not sufficient to buy the good, are consumed. The period 2 self knows that his future self will buy the good if and only if he saves $s_{2} \geq p-1$, and absent shocks. He decides whether to send $s_{2}=p-1$, in which case the good is bought (it is never optimal to send $s_{2}>p-1>1$ ). The alternative is to smooth the existing savings $s_{1}$ over periods 2 and 3 - denote this as $s_{2}^{N o}\left(s_{1}\right)$. The period 2 agent saves iff

$$
u\left(1+s_{1}-(p-1)\right)+\beta[(1-\lambda) u(b)+\lambda u(p-1)] \geq u\left(1+s_{1}-s_{2}^{N o}\right)+\beta E\left[u\left(y_{3}+s_{2}^{N o}\right)\right]
$$

Lemma 1. (a) The period 2 agent is willing to save for the nondivisible and transfer $s_{2}=p-1$ if $s_{1}$ is bigger than some threshold value, $s_{1} \geq s_{\min }$. (b) $s_{\min }$ is strictly decreasing in the timeinconsistency parameter $\beta$. (c) The effect of the shock frequency $\lambda$ on $s_{\min }$ is ambiguous.

(All proofs are in the Online Appendix.)

Analogue to the minimum $s_{1}$ threshold for period 2, it is useful to identify the maximum $s_{1}$ that period 1 is willing to save, conditional on purchase of the nondivisible. This maximum, denoted $s_{\max }$, will increase with $\beta$ (all variables are formally defined in the Appendix). If this maximum is bigger than the minimum required (and no shocks occur), the good will be purchased. Conditional on the nondivisible not being purchased (i.e. $\left.s_{2}=s_{2}^{N o}<p-1\right)$, period 1 saves only for precautionary purposes, $s_{1}^{N o}$. The maximum that period 1 would be willing to save is strictly increasing in the degree of time-inconsistency $\beta$. The interiority of $s_{\max }$ in the relevant range of $\beta$ follows from the desirability of the nondivisible for a time-consistent agent: We know that $s_{\max }(\beta=1) \geq \frac{p-1}{2}$ and that $s_{\max }(0)=0$. The final component to the autarky equilibrium is the optimal way in which period 1 would like to allocate the savings burden of $p-1$ across periods 1 and 2 , denoted $s_{1}=s_{\text {opt }}$. This is the amount of savings period 1 would make if he could dictate his preferences onto his period 2 self. It is strictly increasing in $\beta$, and always smaller than $s_{\max }$.

Proposition 1. (Autarky Equilibrium) Without banking services, the nondivisible good is purchased below a threshold level of time-inconsistency, or for all $\beta \in[\hat{\beta}, 1]$. Absent shocks, equilibrium savings are

$$
s_{1}=\left\{\begin{array}{ll}
\max \left(s_{\min }, s_{\text {opt }}\right) & \text { if } \beta \in[\hat{\beta}, 1] \\
s_{1}^{N o} & \text { if } \beta \in[0, \hat{\beta})
\end{array}, s_{2}= \begin{cases}p-1 & \text { if } \beta \in[\hat{\beta}, 1] \\
s_{2}^{N o} & \text { if } \beta \in[0, \hat{\beta}) .\end{cases}\right.
$$

Given a decreasing $s_{\min }(\beta)$ and an increasing $s_{\max }(\beta)$-function, there is a threshold level $\hat{\beta}$ such that $s_{\min }(\beta) \leq$ $s_{\max }(\beta)$ for any $\beta \geq \hat{\beta}$. The fact that $\hat{\beta}$ is in the relevant interval $(0,1]$ follows from $s_{\min }(0)>s_{\max }(0)$ and $s_{\min }(1) \leq s_{\max }(1)$ : The former follows from $s_{\min }(0)>1, s_{\max }(0)=0$. The latter is a consequence of desirability, by which a time-consistent agent always purchases the good. Since the different period selves are perfectly able to anticipate each other's behaviour, the nondivisible will be purchased (absent shocks) for all $\beta \in[\hat{\beta}, 1]{ }^{11}$

The equilibrium savings path is illustrated in Figure 1. If a shock occurs in any period, the individual gives up any plans to save for the nondivisible, and smoothes available assets $y_{t}+s_{t-1}$ over future periods, saving $s_{t}^{N o} \geq 0$ for all $t$ after the shock. Importantly for the later analysis with commitment, it is ambiguous whether autarky savings will be above or below $\bar{s} \equiv \frac{p-1}{2}$. Considering that a time-consistent agent saves $\bar{s}$ (for $\lambda=0$ ) or slightly below $\bar{s}$ (for $\lambda>0$ ), this question corresponds to O'Donoghue and Rabin's (1999) pre-emptive overcontrol: A sophisticated hyperbolic discounter may both save more or less than a time-consistent agent, depending on the

\footnotetext{
${ }^{11}$ Except for the added possibility of shocks, the autarky result is shared with Basu (2014).
} 


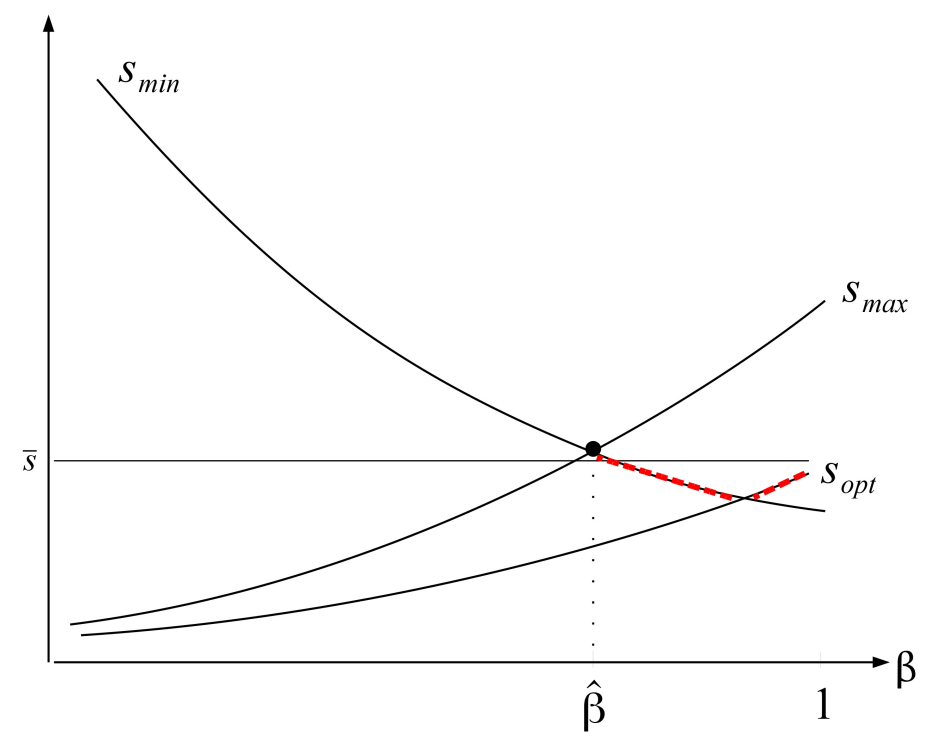

Figure 1: Autarky Equilibrium

Equilibrium savings follow the red dashed line. $s_{\text {min }}$ denotes the minimum savings required in period 1 to induce the period 2 self to save. $s_{\max }$ denotes the maximum savings that the period 1 self is willing to make, conditional on the nondivisible good being bought. $\bar{s} \equiv \frac{p-1}{2}$ is the path of even savings contributions.

numerical values used for $(b-p)$ and $u$ " $(c)$. In the following, autarky scenarios with $s_{\min }(\hat{\beta})=s_{\max }(\hat{\beta})>\bar{s}$ will be characterized as "overcontrol scenarios," whereas those with $s_{\min }(\hat{\beta})=s_{\max }(\hat{\beta})<\bar{s}$ will be referred to as "procrastination scenarios." Either term refers to the equilibrium savings at the threshold level $\hat{\beta}$, regardless of the savings made at other levels of $\beta$.

\subsection{Equilibrium with a Regular Saver Commitment Product}

The autarky equilibrium is inefficient for $\beta<\hat{\beta}$ : The agent is unable to save for the good, despite its desirability. For $\beta \geq \hat{\beta}$, smaller inefficiencies are possible due to a failure to smooth consumption. The following section investigates the effect of offering agents a commitment to fixed regular savings contributions - as commonly found in loan contracts, pension savings, and other forms of regular saving. ${ }^{12}$

The Regular Saver product is defined as follows: The agent can commit in period 0 to deposit a fixed amount $\bar{s}=\frac{p-1}{2}$ in a bank account in both period 1 and 2 . He also chooses a default penalty $D$, subject only to a limited liability constraint which prevents negative consumption. Once the agent fails to deposit $\bar{s}$ in a period, he is charged the default penalty $D$, but immediately receives back any accumulated savings. In addition, he is free to save at home independently of his bank contributions. His total cumulated savings (in the bank plus at home) can be captured as $s_{t}$. The penalty $D$ is imposed in period 1 if $s_{1}<\bar{s}$, and in period 2 if $s_{1} \geq \bar{s}, s_{2}<2 \bar{s}$. The contract is successfully completed with $s_{1} \geq \bar{s}, s_{2} \geq 2 \bar{s}$. The assumption that the contract is signed in period 0 simplifies things greatly, as the agent is not subject to temptation in this period, but it requires the bank to have contract-enforcing power. The commitment adoption decision in period 0 is discussed at the end of this section.

As before, the savings outcome can be derived using backwards induction. As in autarky, the period 3 agent will buy the nondivisible whenever he can afford it, i.e., whenever $s_{2} \geq p-1$ holds, and absent shocks. Period 2

\footnotetext{
${ }^{12}$ Footnote 10 argues that the first-best savings schedule is slightly increasing for $\lambda>0$, i.e., $s_{1}<\bar{s}$. For small $\lambda$, this effect is likely to be small. Commitment products with increasing savings schedules are possible, but may pose serious challenges to institutional implementation: The first-best schedule will depend on individual values of $\lambda, u$ " $(c), p$ and $b$. The present analysis focuses on fixedinstalment products due to their empirical popularity and ease of administration.
} 
is now faced with a penalty $D$ for not saving, conditional on period 1 having transferred $s_{1} \geq \bar{s}$. If period 2 is hit by a shock, default is unavoidable, and a penalty up to the level of his assets, $D \leq s_{1}$, can be enforced. Absent shocks, period 2 is willing to transfer $s_{2}=2 \bar{s}=p-1$ if and only if he receives sufficient savings from period 1 . This results in a new threshold of minimum period 1 savings, $s_{1} \geq s_{\min }^{B}$, above which the nondivisible good will be bought. The new threshold $s_{\min }^{B}(\beta)$ will be strictly lower than $s_{\min }(\beta)$ in the autarky case: Not saving becomes less attractive (see Figure 2). The effect of the penalty disappears for $s_{1}<\bar{s}$ : Period 1 has already defaulted on the contract and paid the penalty, so the contract is no longer active in period 2. As a result, $s_{\min }^{B}(\beta)=s_{\min }(\beta)$ for $s_{1}<\bar{s}^{13}$

The situation is more complicated for the period 1 agent: He faces the penalty $D$ with positive probability, both if he saves and if he does not: First, the penalty is imposed following a deliberate decision to default in period $1, s_{1}<\bar{s}$. Second, even a devoted saver risks losing his savings in case of a shock in period 2. Limited liability implies that, in case of a shock, the penalty can only be imposed on existing savings, since current income is lost. Thus, the penalty is never enforceable if a shock hits in period 1 , and in period 2 only if period 1 has left savings.

Lemma 2. For small shock frequencies $\lambda$, and in the region where savings are skewed towards period $1, s_{1} \geq \bar{s}$, adopting a regular-instalment product increases the maximum the agent is willing to save, i.e., $s_{\max }^{B}>s_{\max }$. A sufficient constraint on the shock frequency is $\lambda<\frac{u^{\prime}(1)}{u^{\prime}(0.5)}$. In the region $s_{1}<\bar{s}$, adopting the regular-instalment product unambiguously decreases $s_{\max }$.

Note that the maximum period 1 is willing to save, $s_{\max }^{B}(\beta)$, increases with the penalty only in the region $s_{1} \geq \bar{s}$ : The decision to save for the nondivisible good coincides with the decision to avoid the penalty. Consider the case where necessary savings are $s_{1}<\bar{s}$, i.e., period 1 could ensure the good is bought even if he does not contribute $\bar{s}$. In this case, he faces a penalty whether or not he saves for the good. The resulting threshold $s_{\max }^{B}(\beta)$ is strictly lower than the original threshold $s_{\max }(\beta)$ (see Figure 2).

Following a similar intuition, the optimal way in which period 1 would like to save for the good, $s_{\text {opt }}$, necessarily decreases under the penalty: $s_{o p t}^{B}<s_{\text {opt }}$. This follows from the fact that $s_{o p t}$ is strictly below $\bar{s}$ in autarky. In order to maintain this preference for pushing the lion's share of the savings burden to period 2, period 1 now needs to pay a "premium" of $D$, which further decreases his willingness to save. Alternatively, period 1 may prefer to jump to $s_{1}=\bar{s}$ to avoid the penalty. This results in a dominated region $[\hat{s}(\beta), \bar{s})$ for some threshold $\hat{s}(\beta)<\bar{s}-D$, illustrated in Figure 2. This dominated region is only defined for $\beta$ such that $s_{\max }^{B}(\beta) \geq \bar{s}$, because it requires that the agent prefers to save $\bar{s}$ over giving up on the nondivisible good altogether. As $\beta$ increases, a larger range of savings $s_{1} \in(\hat{s}(\beta), \bar{s})$ is strictly dominated (equivalently, $\hat{s}(\beta)$ weakly decreases in $\beta$ ).

\section{Equilibrium and Contract Choice}

The nondivisible is purchased whenever $s_{\max }^{B}(\beta) \geq s_{\min }^{B}(\beta)$, which occurs for any $\beta \in\left[\hat{\beta}_{B}, 1\right]$. Equilibrium savings (absent shocks) are analogue to those for autarky, except for a lower savings threshold $\hat{\beta}_{B}<\hat{\beta}$, and a dominated region $s_{1} \in[\hat{s}(\beta), \bar{s})$ :

$$
s_{1}= \begin{cases}\max \left(s_{\text {min }}^{B}, s_{o p t}^{B}\right) & \text { if } \beta \in\left[\hat{\beta}_{B}, 1\right] \text { and } \max \left(s_{\text {min }}^{B}, s_{o p t}^{B}\right) \notin[\hat{s}, \bar{s}) \\
\bar{s} & \text { if } \beta \in\left[\hat{\beta}_{B}, 1\right] \text { and } \max \left(s_{\text {min }}^{B}, s_{\text {opt }}^{B}\right) \in[\hat{s}, \bar{s}), s_{2}=\left\{\begin{array}{ll}
p-1 & \text { if } \beta \in\left[\hat{\beta}_{B}, 1\right] \\
s_{1}^{N o} & \text { if } \beta \in\left[0, \hat{\beta}_{B}\right)
\end{array} \quad \text { if } \beta \in\left[0, \hat{\beta}_{B}\right) .\right.\end{cases}
$$

\footnotetext{
${ }^{13}$ The two sections of the $s_{\min }^{B}(\beta)$-function combine with a horizontal line at $s_{\min }^{B}(\beta)=\bar{s}=\frac{p-1}{2}$. In this region, the $s_{\min }$ required by period 2 is lower than $\bar{s}$ if he faces the penalty, and higher than $\bar{s}$ if he does not. To keep the contract active and ensure that period 2 faces the penalty, the period 1 agent needs to save $s_{1} \geq \bar{s}$.
} 


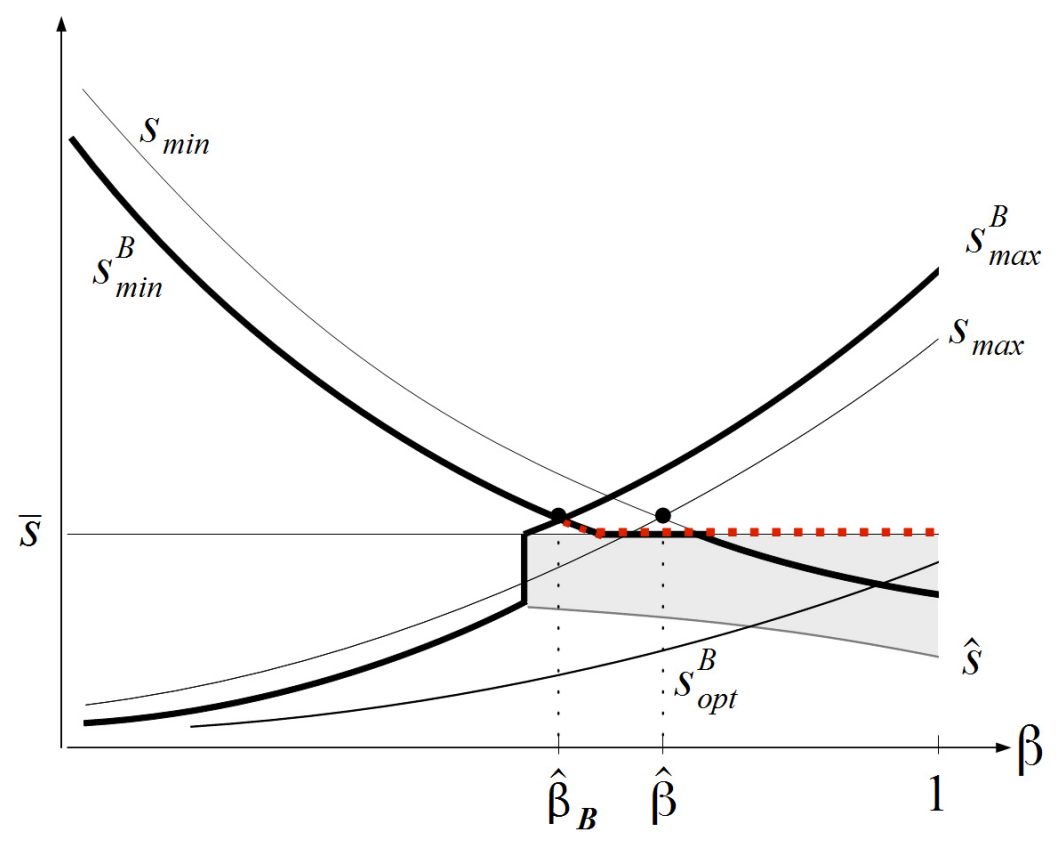

Figure 2: Regular Saver Equilibrium (overcontrol scenario)

Equilibrium savings follow the red dashed line. The nondivisible good can be achieved for $\beta \in\left[\hat{\beta}_{B}, 1\right]$ with the regular saver product, and for $\beta \in[\hat{\beta}, 1]$ in autarky. In an overcontrol scenario, the autarky equilibrium savings at the threshold level $\hat{\beta}$ exceed the balanced savings path, $\bar{s} \equiv \frac{p-1}{2}$.

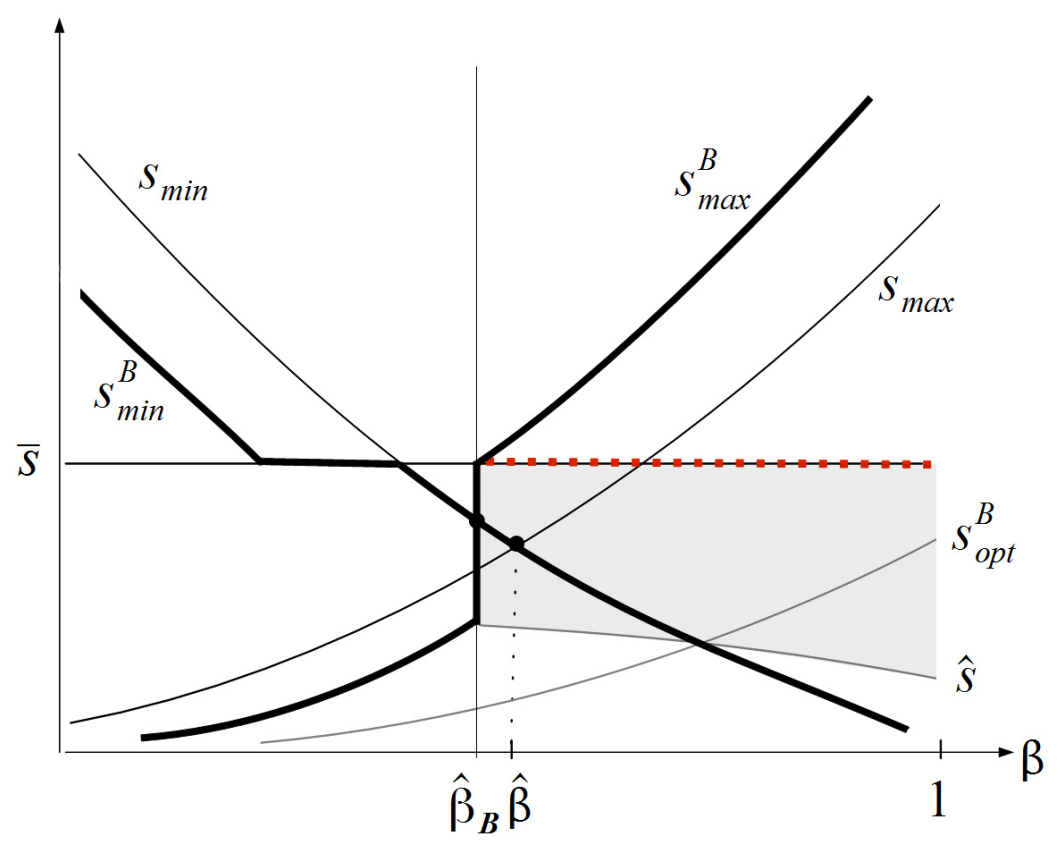

Figure 3: Regular Saver Equilibrium (procrastination scenario)

Equilibrium savings follow the red dashed line. The nondivisible good can be achieved for $\beta \in\left[\hat{\beta}_{B}, 1\right]$ with the regular saver product, and for $\beta \in[\hat{\beta}, 1]$ in autarky. In a procrastination scenario, the autarky equilibrium savings at the threshold level $\hat{\beta}$ stay below the balanced savings path, $\bar{s} \equiv \frac{p-1}{2}$. 
Figure 2 shows the equilibrium savings path in autarky settings characterized by overcontrol, while Figure 3 starts from autarky settings with procrastination (as defined in Section 2.2).

Proposition 2. (Commitment Equilibrium) Offering a regular saver commitment product makes the nondivisible good achievable under a larger range of preferences, $\beta \in\left[\hat{\beta}_{B}, 1\right]$, instead of $\beta \in[\hat{\beta}, 1]$ in the autarky benchmark. A lower threshold $\hat{\beta}_{B} \leq \hat{\beta}$ emerges for any positive penalty $D>0$ if the autarky setting is characterized by preemptive overcontrol. In settings characterized by procrastination, a sufficiently large penalty $D$ is required to guarantee $\hat{\beta}_{B} \leq \hat{\beta}$.

Proposition 3. For those already able to save in autarky, $\beta \geq \hat{\beta}$, the adoption of a regular saver product weakly smoothes savings contributions (and thus consumption) towards $\bar{s}$.

Period 0 Adoption Decision and Penalty Choice In principle, any agent with $\beta \in[0,1)$ can benefit from commitment. Given a sufficiently large penalty, it makes the nondivisible achievable and smoothes savings: Absent shocks, the contract is trivially enforceable in period 1 if $D>\bar{s}$, and in period 2 if $D>2 \bar{s}$. As a result, the threshold $\hat{\beta}_{B}$ can be moved to an arbitrarily low $\beta$. The downside of commitment is the risk of "rational default" due to shock frequency $\lambda$ : The penalty not only acts to discipline the agent when income is available, it also needs to be paid when the agent no longer finds it welfare-maximising (or feasible) to save for the nondivisible.

The resulting decision is a two-step problem: The period 0 agent first decides which penalty $D$ offers the optimal trade-off between commitment and flexibility (denoted $D^{*}$ ). He then makes a binary choice between adopting the regular saver product with the optimal penalty, or not adopting the product. The choice of $D^{*}$ is complex: Due to the consumption smoothing motive, $D^{*}$ is non-monotonic in $\beta$, and sensitive to the autarky scenario. To see this, define $D_{\min }(\beta)$ to be the minimum effective penalty which achieves $s_{\max }^{B}(\beta) \geq s_{\min }^{B}(\beta)$, and thus makes the nondivisible good achievable. In overcontrol settings, $D_{\min }$ generally results in equilibrium savings that are skewed towards period 1 (as at $\beta=\hat{\beta}_{B}$ in Figure 2). Increasing $D$ further smoothes savings towards $\bar{s}$. The associated benefit is small and continuous, as opposed to the large discrete benefit from obtaining the nondivisible good. Whether the agent deems it worthwhile to increase $D$ beyond $D_{\min }$ will depend on the involved uncertainty $\lambda$ as well as his preference for consumption smoothing $u$ " $(c)$. Finally, non-monotonicity of the optimal penalty $D^{*}$ follows from the non-monotonicity of the equilibrium savings path in autarky, $s_{1}=\max \left(s_{\min }, s_{\text {opt }}\right)$. Individuals who are able to save in autarky (those with $\beta \geq \hat{\beta}$ ) can use $D$ to create a dominated region $[\hat{s}(\beta), \bar{s})$ that includes their current savings level $s_{1}$, causing them to jump to $\bar{s}$. As $\beta$ increases, autarky equilibrium savings first decrease along $s_{\min }$, and then increase along $s_{\text {opt }}$. Analogously, the penalty required to make the agent jump to $\bar{s}$ first increases and then decreases with $\beta .{ }^{14}$ As a result, the commitment adoption decision is likely to be non-monotonic for $\beta \in[\hat{\beta}, 1)$.

For the sake of simplicity, I abstract from the consumption smoothing motive, and focus on the range of $\beta \in[0, \hat{\beta})$. For this range, the nondivisible is not achievable in autarky, and obtaining it constitutes the primary benefit of the Regular Saver product. This focus is empirically meaningful: It restricts the analysis to the part of the population who are not able to save for lump-sum consumption expenditures by themselves. Given full sophistication, a Regular Saver contract with a penalty $D_{\min }$ will enable the agent to save for the nondivisible (absent shocks). By construction, $D_{\min }=0$ for $\beta \geq \hat{\beta}$.

Proposition 4. For a given shock frequency $\lambda$, the minimum effective penalty $D_{\text {min }}$ that will enforce saving weakly decreases in the time-inconsistency parameter $\beta$.

\footnotetext{
${ }^{14}$ Formally, the agent will choose $D$ such that $\hat{s}(\beta)=\max \left(s_{\min }^{B}, s_{\text {opt }}^{B}\right)$ holds exactly.
} 
Proposition 5. (Optimal Penalty Choice) (a) In autarky settings characterized by procrastination, the minimum penalty required to obtain the nondivisible good, $D_{\min }$, also guarantees perfect consumption smoothing, with $s_{1}=\bar{s} \equiv \frac{p-1}{2}$ and $s_{2}=2 \bar{s}=p-1$. Consequently, the optimal contract is to choose $D_{\text {min }}$. (b) In autarky settings characterized by overcontrol, $D_{\min }$ fails to guarantee consumption smoothing. The optimal contract involves $D \geq D_{\text {min }}$, with equilibrium savings weakly skewed towards period $1\left(s_{1} \geq \bar{s}\right)$.

In settings involving pre-emptive overcontrol, penalties exceeding $D_{\min }$ are most likely to be chosen when the motive for consumption smoothing is large. This occurs for high autarky savings $s_{\min }(\hat{\beta})=s_{\max }(\hat{\beta}) \gg \bar{s}$, small shock frequencies $\lambda$ (so the agent is less averse to big penalties), and large nondivisible prices $p$ (increasing the benefits to consumption smoothing).

Having determined $D^{*}$, the period 0 agent faces the binary decision of whether or not to take up the Regular Saver product. The adoption decision is characterized in Proposition 6.

Proposition 6. (Commitment Adoption Decision) (a) Adoption of the Regular Saver product decreases in the shock frequency $\lambda$, the nondivisible price $p$, and the required penalty $D_{\min }$. Adoption increases in the nondivisible good's benefit $b$. (b) Conditional on being unable to save in autarky $(\beta<\hat{\beta})$, those with the highest amount of time-inconsistency are the least likely to adopt commitment (i.e., adoption increases in $\beta$ ), as the most timeinconsistent agents require the largest penalties.

The key to Proposition 6 is that the benefit of an effective commitment contract (obtaining the nondivisible good at smooth savings $s_{1}=\bar{s}$ ) is independent of $\beta$ : The period 0 agent bases his adoption decision on the welfare function $W=E\left[u\left(c_{1}\right)+u\left(c_{2}\right)+u\left(c_{3}\right)\right]$, which does not directly depend on $\beta \cdot{ }^{15}$ Put simply, the time-inconsistency parameter $\beta$ determines how difficult it is for the agent to save for the nondivisible, but not how much he benefits from achieving it. As a result, agents with low $\beta$ (and thus a high required penalty $D_{\min }$ ) will find commitment unattractive in expectation.

Welfare Implications Given full sophistication, agents assess the optimal degree of commitment $D^{*}$ correctly. Everyone who adopts the commitment product is made better off in expectation. Ex-post welfare losses occur due to shocks, causing a fraction $\lambda$ of adopters to default each period. In summary, offering regular-instalment savings products is weakly welfare-increasing for sophisticated hyperbolic discounters, and strictly welfare-increasing for those who adopt it.

\subsection{Loans}

The introductory section hypothesized that individuals may use loans to obtain a commitment to fixed regular instalments, when (cheaper) savings products with such commitment features are not available. This section formalises this argument. As before, suppose that the individual has a consumption opportunity in period 3, which costs $p$ and yields benefit $b$. Extend the time horizon to five periods: The agent can either save for the good in periods 1 and 2, or he can take a loan in period 3, and repay it in periods 4 and 5 . The timing of the consumption opportunity is the same in both cases in order to reflect the 'save before or borrow after' decision of many anticipated expenditures (such as school fees). To illustrate the simplest possible mechanism, abstract from uncertainty, and assume that an incentive-compatible loan enforcement mechanism is available. ${ }^{16}$

\footnotetext{
${ }^{15}$ The result that the benefit obtained from commitment is independent of $\beta$ holds exactly for $\lambda=0$, and to a first-order approximation for $\lambda>0$. For $\lambda>0$, the agent values precautionary savings, which decrease in $\beta$. Commitment thus provides an insurance value which increases in $\beta$. However, this is a second-order effect which is quantitatively dominated by the offputting effect of a higher required penalty $D_{\min }$.

${ }^{16}$ All basic conclusions will hold when allowing for uncertainty. However, the marginal trade-off between savings and loan products will shift with differences in the enforcement technology, since the good is consumed before the loan is repaid.
} 
Assume a benchmark setting like that described in Section 2.2, except that loans are now available. The agent can borrow $p-1$ at a per-period gross interest rate of $R$ in order to buy the nondivisible good in period 3 . Repayment follows in two equal instalments of $\frac{R^{2}}{R+1} \cdot(p-1)$ in periods 4 and $5 .{ }^{17}$ An argument similar to that for the savings product can be used to show that frequent loan instalments are preferable to one single repayment from both enforcement and welfare perspectives (see also Fischer and Ghatak (2010)). It is convenient to define $L \equiv u(b)+2 u\left(1-\frac{R^{2}}{R+1} \cdot(p-1)\right)$ for the utility derived from loans in periods 3 to 5 . Finally, assume $R$ and $b$ such that the individual prefers loan-financed consumption over not consuming the good, i.e. $L \geq 3 u(1)$.

The savings analysis is akin to that of the previous sections, except that credit-financed consumption replaces 'not consuming the good' as the outside option. As in the autarky setting (Section 2.2), the welfare-maximising choice is to save for the nondivisible good at home, which is cheaper than a loan. However, the period 1 and 2 selves disagree about how to split the savings burden between them. A new $s_{\min }$ and $s_{\max }-$ curve result, with a new threshold $\beta \geq \hat{\beta}_{L}$, above which the agent is able to save independently. Since the loan provides a weakly better outside option than not consuming the good, the range of $\beta$ where the agent saves at home is reduced, i.e. $\hat{\beta}_{L} \geq \hat{\beta}$. Agents with $\beta<\hat{\beta}_{L}$ resort to loan financing. Notably, a monopolist moneylender could set $R$ such that $L=3 u(1)$ holds with equality, implying $\hat{\beta}_{L}=\hat{\beta}$. In this case, there is no welfare benefit from the availability of loans.

Introducing a commitment savings product into this setting is analogous to Section 2.3: A fully sophisticated period 0 planner will sign a commitment contract with an optimal penalty $D^{*}$, which ensures that he can reach the nondivisible good without resorting to expensive loans, and which helps to smooth his savings contributions. In this simplified setting, the savings product is preferable to the loan for all $R>1$, noting that the planner values all periods equally. Adding exponential discounting $(\delta<1)$, uncertainty, and differences in enforcement technology will affect the marginal trade-off between savings and loans. However, the basic result remains: In absence of commitment savings products, a time-inconsistent individual is likely to use loans to overcome savings constraints. As illustrated in Section 1, these loans can be very expensive, especially when used in repeated cycles. The introduction of a regular-instalment product provides an alternative, cheaper means to overcome savings constraints, and thus increases the agent's welfare.

\section{Discussion}

In attempting to explain the large observed demand for costly informal savings devices, this paper has outlined the benefits of regular-instalment commitment savings products for hyperbolic discounters. Specifically, such products can help to make lump-sum expenses achievable, encourage balanced savings paths, and reduce the demand for high-interest loans. Commitment devices with fixed regular instalments are relatively easy to implement in rich countries, where people's financial lives are largely automated. Any commercial bank will allow a client to set up a regular monthly direct debit from his income, before he has the opportunity to spend it. Such commitments are 'soft', in that they do not feature penalties for cancelling the service. Instead, they work via mental accounting, default option effects, and transaction costs (see Benartzi and Thaler (2004) for an application to pension contributions in the U.S.). Introducing formal commitments to regular instalments is more challenging in developing countries, where the use of direct debits is much less common. In many cases, people receive their income in cash, and need to walk to the bank to make regular deposits. In such cases, the use of self-chosen default penalties can be useful to implement commitment in practice. An empirical companion paper, John (2016), introduces and studies such a regular-instalment product in the Philippines, and finds large increases on savings levels on average.

\footnotetext{
${ }^{17}$ The calculation of two equal instalments $I$ follows from $I+R \cdot I=R^{2}(p-1)$.
} 
However, the study also serves as a cautionary note: In order to adopt welfare-increasing commitment products, individuals need to be sophisticated about their time-inconsistency. If, instead, sophistication is incomplete, then agents may choose commitment products which are too weak to make them save, leading to welfare losses. Thus, attention needs to be paid to the suitability of commitment products for the preferences of those who adopt them.

\section{References}

Afzal, Uzma, Giovanna d'Adda, Marcel Fafchamps, Simon Quinn, and Farah Said. 2015. "Two Sides of the Same Rupee? Comparing Demand for Microcredit and Microsaving in a Framed Field Experiment in Rural Pakistan." Centre for the Study of African Economies Working Paper.

Amador, Manuel, Iván Werning, and George-Marios Angeletos. 2006. “Commitment vs. Flexibility.” Econometrica, 74(2): 365-396.

Ananth, Bindu, Dean Karlan, and Sendhil Mullainathan. 2007. "Microentrepreneurs and Their Money: Three Anomalies.” Financial Access Initiative Working Paper.

Ashraf, Nava, Dean Karlan, and Wesley Yin. 2006. "Tying Odysseus to the Mast: Evidence from a Commitment Savings Product in the Philippines.” Quarterly Journal of Economics, 121(2): 635-672.

Basu, Karna. 2014. "Commitment Savings in Informal Banking Markets.” Journal of Development Economics, 107: 97-111.

Bauer, Michal, Julie Chytilova, and Jonathan Morduch. 2012. "Behavioral Foundations of Microcredit: Experimental and Survey Evidence from Rural India.” American Economic Review, 102(2): 1118-1139.

Benartzi, Shlomo, and Richard H. Thaler. 2004. "Save More Tomorrow: Using Behavioral Economics to Increase Employee Saving.” Journal of Political Economy, 112(1): 164-187.

Besley, Timothy. 1995. "Savings, Credit and Insurance.” In Handbook of Development Economics. Vol. 3A, , ed. Jere Behrman and T.N. Srinivasan. Elsevier.

Besley, Timothy, Stephen Coate, and Glenn Loury. 1993. "The Economics of Rotating Savings and Credit Associations." American Economic Review, 83(4): 792-810.

Brune, Lasse, Xavier Giné, Jessica Goldberg, and Dean Yang. 2016. "Facilitating Savings for Agriculture: Field Experimental Evidence from Malawi." Economic Development and Cultural Change, 64(2): 187-220.

Collins, Daryl, Jonathan Morduch, Stuart Rutherford, and Orlanda Ruthven. 2009. Portfolios of the Poor How the World's Poor Live on \$2 a Day. Princeton:Princeton University Press.

Crosgrave, Lloyd M. 1927. “Christmas Clubs.” The Quarterly Journal of Economics, 41(4): 732-739.

Dupas, Pascaline, and Jonathan Robinson. 2013. "Why Don't the Poor Save More? Evidence from Health Savings Experiments." American Economic Review, 103(4): 1138-71.

Fischer, Greg, and Maitreesh Ghatak. 2010. "Repayment Frequency in Microfinance Contracts with PresentBiased Borrowers.” London School of Economics EOPP Discussion Papers 21. 
Giné, Xavier, Dean Karlan, and Jonathan Zinman. 2010. "Put Your Money Where Your Butt Is: A Commitment Contract for Smoking Cessation.” American Economic Journal: Applied Economics, 2(4): 213-235.

Gugerty, Mary Kay. 2007. "You Can't Save Alone: Commitment in Rotating Savings and Credit Associations in Kenya." Economic Development and Cultural Change, 55(2): 251-282.

John, Anett. 2016. "When Commitment Fails - Evidence from a Field Experiment." London School of Economics EOPP Discussion Papers 55.

Karlan, Dean, Margaret McConnell, Sendhil Mullainathan, and Jonathan Zinman. 2016. "Getting to the Top of Mind: How Reminders Increase Saving.” Management Science, 62(12): 3393-3411.

Kast, Felipe, Stephan Meier, and Dina Pomeranz. 2014. "Under-Savers Anonymous: Evidence on Self-Help Groups and Peer Pressure as a Savings Commitment Device." National Bureau of Economic Research Working Paper 20239.

Laibson, David. 1997. "Golden Eggs and Hyperbolic Discounting." Quarterly Journal of Economics, 112(2): 443-478.

Laibson, David I, Andrea Repetto, Jeremy Tobacman, Robert E Hall, William G Gale, and George A Akerlof. 1998. "Self-Control and Saving for Retirement." Brookings Papers on Economic Activity, 1: 91-196.

O'Donoghue, Ted, and Matthew Rabin. 1999. "Doing It Now or Later." American Economic Review, 89(1): 103-124.

Rutherford, Stuart. 2000. The Poor and Their Money. Oxford:Oxford University Press. 